\title{
Differences in Atrial Fibrillation Management Strategies among Physicians: A Survey Based Study
}

\author{
Sara Cetin Sanlialp, Ugur Onsel Turk', Kaan Okyay², Ozcan Basaran ${ }^{3}$, Ugur Canpolat ${ }^{4}$, Mehdi Zoghi ${ }^{5}$ \\ Department of Cardiology, Servergazi State Hospital, Denizli, ${ }^{1}$ Department of Cardiology, KardiyoRitm Cardiac Health Center, \\ ${ }^{5}$ Department of Cardiology, Ege University Faculty of Medicine, Izmir, ${ }^{2}$ Department of Cardiology, Baskent University Hospital, ${ }^{4}$ Department of Cardiology, \\ Hacettepe University Faculty of Medicine, Ankara, ${ }^{3}$ Department of Cardiology, Mugla University, Mugla, Turkey \\ ORCID: \\ Sara Cetin Sanlialp: https://orcid.org/0000-0001-9328-9197 \\ Ugur Onsel Turk: https://orcid.org/0000-0001-6348-6616 \\ Kaan Okyay: https://orcid.org/0000-0001-6134-8826 \\ Özcan Basaran: https://orcid.org/0000-0002-6384-6455 \\ Ugur Canpolat: https://orcid.org/0000-0002-4250-1706 \\ Mehdi Zoghi: https://orcid.org/0000-0002-0988-7061
}

\section{Abstract}

Aim: Previous data reflected confusions about classification and management of atrial fibrillation (AF) among physicians. Although relatively clear suggestions of dedicated guidelines, poor adaptation of them to routine clinical practice may result with suboptimal prevention and treatment measures. As a main stakeholder of management, physicians' perceptions about the disease have major role. The study aimed to assess confusions and concordances of physicians about the definition and management of the disease. Methods and Results: We developed a web-based survey about AF consisting of 27 questions regarding valvular or non-valvular AF perception, using thromboembolic and bleeding risk scores, antithrombotic management and rate/rhythm control strategies. Two hundred and thirty two physicians participated and 224(97\%) of them completed the survey. Although only cardiologists were invited to the survey, 27 physicians from different specialties also responded the survey. Half of the physicians reported that $\geq 40 \%$ of their patients had valvular AF. Dramatically, the survey responses revealed that nearly one-third of physicians classified the AF patients with mitral regurgitation as valvular AF. Most of the physicians denoted that they were using bleeding and stroke risk scores before deciding oral anticoagulation therapy and also preferring long term rhythm-control strategy in AF patients with systolic heart failure. However, results exposed evident disparities among physicians at specific aspects of the disease management. Conclusion: The survey-based study demonstrated a great heterogeneity in classification and management of AF among physicians because of guideline confusions/failures, inadequate evidence about some specific conditions and not being able to dominate the guidelines by physicians.

Keywords: Atrial fibrillation, management, physician, survey

\section{INTRODUCTION}

Atrial fibrillation (AF) is an independent risk factor for stroke and a significant predictor of mortality. Evidence-based AF guidelines recommend antithrombotic therapy corresponding to the risk of stroke. ${ }^{[1]}$ In practice, many patients with AF do not receive the appropriate antithrombotic therapy and are left either unprotected or inadequately protected against the risk of stroke. ${ }^{[2]}$ Valvular AF has gained importance after the

Submission: 08-Dec-18 Revision: 02-Jan-19 Accepted: 13-Jan-19

\section{Access this article online}

\begin{tabular}{|l|l|}
\hline \multicolumn{2}{|c|}{ Access this article online } \\
\hline Quick Response Code: & Website: \\
& http://www.ijcva.com \\
\cline { 2 - 2 } & \\
\end{tabular}

introduction of non-Vitamin $\mathrm{K}$ antagonists (NOACs) taking into account their contraindications. ${ }^{[3]}$ The current guidelines have provided clear definition of the valvular AF ${ }^{[1]}$ Previous physician surveys showed heterogeneity in the perception of valvular AF

Address for correspondence: Dr. Sara Cetin Sanlialp, Department of Cardiology, Servergazi State Hospital, Bereketler Mahallesi, Bereket Cd. No. 1, 20000 Merkezefendi-Denizli, Turkey. E-mail: saracetin@hotmail.com.tr

This is an open access journal, and articles are distributed under the terms of the Creative Commons Attribution-NonCommercial-ShareAlike 4.0 License, which allows others to remix, tweak, and build upon the work non-commercially, as long as appropriate credit is given and the new creations are licensed under the identical terms.

For reprints contact: reprints@medknow.com

How to cite this article: Sanlialp SC, Turk UO, Okyay K, Basaran O, Canpolat U, Zoghi M. Differences in atrial fibrillation management strategies among physicians: A survey based study. Int J Cardiovasc Acad 2019;5:58-65. 
and variable thromboprophylactic strategies among physicians, particularly in the case of mitral regurgitation. ${ }^{[4]}$ Furthermore, recent European Heart Rhythm Association (EHRA) survey showed striking discordances in the definition and assessment strategies of valvular $\mathrm{AF}^{\left[{ }^{[3]}\right.}$ The treatment threshold for the use of oral anticoagulants (OAC) differs between the current guidelines. Similarly, there is a controversy among the current guidelines regarding antithrombotic agent selection. Although according to the ACC/AHA/HRS guidelines aspirin (ASA) continues to have a role in the treatment of patients who have low stroke risk and cannot use OACs, the European Society of Cardiology (ESC) guidelines have entirely eliminated the use of ASA. ${ }^{[1,5]}$ These controversies in the guidelines may lead to significant differences in patient management in clinical practice.

NOACs have been emerged as an alternative to Vitamin K antagonists (VKAs) for thromboembolic prevention in $\mathrm{AF}$ patients. However, compared with VKAs, the proper use of NOACs requires many practical aspects. Practical guidelines about how to deal with NOACs in specific clinical situations have been published and updated by The European Heart Rhythm Association in recent years. ${ }^{[6,7]}$ Implementation of this guidance in clinical practice remained unclear.

The purpose of the survey was to obtain possible discrepancies on perception and management strategies of AF expressed by physicians in Turkey.

\section{The methodology of the survey}

We prospectively conducted a web-based survey for the opinions of physicians about AF. The study population was selected from a database composed of physicians who attended to the scientific activities of Society of Cardiovascular Academy. An electronic link of the questionnaire was sent to their E-mail addresses. The link deactivated after 6 months. The survey was voluntary, and no grant was given to the participants. Informed consent to participate in the survey and publication of the data was obtained by all involved physicians through Q26.

\section{Questionnaire development}

The questionnaire was developed by the second and last authors. Most of the questions were based on a multiple choice format. Due to the structure of the electronic questionnaire, skipping to the next question without giving an answer to the current question had not been allowed. The study was conducted according to the Declaration of Helsinki and its subsequent modifications. The demographic and personal data of each physician participated in the present survey were carefully preserved and strictly protected. The study was approved by the local ethics committee (Ege University, 26/01/2017-E.21845, 17-1.1/2).

\section{Survey questionnaire}

The survey questionnaire included a total of 26 questions addressing the following items: (1) Occupational demographics of physicians (Q01-Q05); (2) Perception of valvular AF (Q06-Q09); (3) Using stroke, bleeding

\begin{tabular}{lc}
\hline Table 1: Occupational demographics of physicians \\
participating in the survey & \\
\hline Question (n/text) & Answers, $\boldsymbol{n}(\%)$ \\
\hline Q1. What is your area of expertise? & \\
Cardiology & $197(87.95)$ \\
Cardiovascular surgery & $10(4.46)$ \\
Internal diseases & $5(2.23)$ \\
Neurology & $3(1.34)$ \\
Emergency & $3(1.34)$ \\
Family medicine & $6(2.68)$ \\
Q2. How many years do you work as a physician? & \\
$<5$ & $20(8.93)$ \\
5-10 & $79(35.27)$ \\
$>10$ & $125(55.80)$ \\
Q3. What is your academic status? & \\
Trainer & $17(7.59)$ \\
Specialist & $127(56.70)$ \\
Assistant professor & $23(10.27)$ \\
Associated professor & $37(16.52)$ \\
Professor & $20(8.93)$ \\
Q4. In which institution are you working? & \\
Private hospital/medicine center & $43(19.19)$ \\
Education Research Hospital, State Hospital & $15(51.34)$ \\
University & $61(27.23)$ \\
Family health center & $5(2.23)$ \\
Q5. How often do you experience atrial fibrillation & \\
in 1 month? & \\
5\%-10\% & $67(29.91)$ \\
$11 \%-20 \%$ & $87(38.84)$ \\
$21 \%-30 \%$ & $53(23.66)$ \\
$31 \%-40 \%$ & $10(4.46)$ \\
$>40 \%$ & $7(3.13)$ \\
\hline & \\
& \\
&
\end{tabular}

risk scores and antithrombotic management strategies (Q10-Q12, Q16-Q17-Q20); (4) OAC therapy at specific scenarios (Q14-Q15, Q18, Q21-Q25); (5) Rhythm/Rate Control Strategies (Q13, Q19). The questionnaires were completed between January 2017 and July 2017.

\section{Data analysis}

Data were collected within the SurveyMonkey web site, exported to Excel (Microsoft, Redmond, WA) format, and imported into IBM SPSS (version 22.0 for Windows, Armonk, NY, USA) for statistical analysis. The answers to all questions were summarized as frequency counts and percentages. Because of the structure of the questionnaire, unanswered questions were not possible.

\section{RESULTS}

The physician population included 197 cardiologists (88\%), 10 cardiovascular surgeons (4.5\%), 6 family physicians $(2.7 \%)$, 5 internists $(2.2 \%), 3$ neurologists $(1.3 \%)$, and 3 emergency physicians $(1.3 \%)$. Of the 224 respondents, $125(55.8 \%)$ had been in practice for $>10$ years, and $115(51.3 \%)$ of them were working in education, research, and state hospital. Distribution of their academic degrees was as follows: $127(56.7 \%)$ 
specialists, $37(16.5 \%)$ associated professors, $23(10.3 \%)$ assistant professors, 20 (8.9\%) professors, and $17(7.6 \%)$ trainees. Occupational demographics of the population are detailed in Table 1.

Half of the physicians estimated that nonvalvular AF would account for $\geq 40 \%$ of all AF patients. A minority of the physicians $(8.5 \%)$ thought that AF was valvular when associated with mitral regurgitation irrespective of its etiology and severity. Interestingly, $28 \%$ of physicians submitted that they decided valvular or nonvalvular AF according to the severity of mitral regurgitation [Figure 1]. While $74 \%$ of the physicians did not consider ischemic mitral insufficiency as valvular AF, $14 \%$ of them accepted $3^{\text {rd }}$ degree and more mitral insufficiency as valvular AF. Nearly $43 \%$ of the physicians thought that mitral insufficiency did not decrease the risk of thrombosis in the left atrium and appendix [Table 2].

Although $63 \%$ of physicians preferred to use OACs in AF patients who had $\mathrm{CHA}_{2} \mathrm{DS}_{2}$ VASc score 1 for males (two for females), $21 \%$ of them specified ASA preference. Majority of physicians remarked $\mathrm{CHA}_{2} \mathrm{DS}_{2}$ VASc score (97\%) using for stroke risk classification and HAS-BLED score using (83\%) for bleeding risk. The proportion of physicians using other bleeding risk scores was only $3 \%$. While $26 \%$ of the physicians preferred ASA in older patients, more than half of the physicians did not prefer ASA in AF. Most of the physicians (71\%) preferred to use $\mathrm{CHA}_{2} \mathrm{DS}_{2} \mathrm{VASc} \geq 2$ for the initiation of OACs in females with AF. According to almost half of the physicians, the daily doses of the NOACs (once or twice a day) were not important, but the other half of them did not agree [Table 3].

More than half of the physicians did not change doses of warfarin at the level of 1.9 INR in elderly patients. About $38 \%$ of physicians did not accept contraindications about OACs. About $48 \%$ of physicians did not prefer to use OACs therapies if the patient had any history of intracranial hemorrhage. In addition, $30 \%$ of the physicians did not consider giving OACs treatment in patients with a history of gastrointestinal bleeding. Nearly two-thirds of the physicians preferred to switch NOAC to warfarin if renal functions had decreased due to chronic diseases. In the case of the acute coronary syndrome, $75 \%$ of physicians pointed out clopidogrel preference in AF patients using OACs.

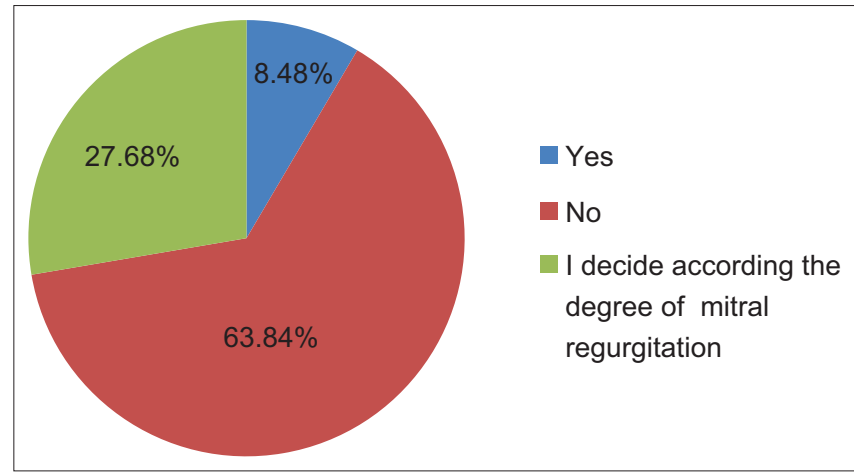

Figure 1: The ratio of physicians answering mitral regurgitation with atrial fibrillation patients as Valvular-atrial fibrillation
Only two physicians responded prasugrel preference [Figure 2]. More than half of the physicians considered switching warfarin to NOACs in AF patients who had low TTR levels, stroke/ transient ischemic attack (TIA)/bleeding under warfarin and

\begin{tabular}{lc}
\hline $\begin{array}{l}\text { Table 2: Perception of nonvalvular atrial fibrillation by } \\
\text { physicians }\end{array}$ \\
\hline Question ( $\boldsymbol{n}$ /text) & Answers, $\boldsymbol{n}$ (\%) \\
\hline Q6. How many percentage of the cases you accept & \\
as NVAF? & $29(12.95)$ \\
$5-10$ & $20(8.93)$ \\
$11-20$ & $33(14.73)$ \\
$21-30$ & $30(13.39)$ \\
$31-40$ & $112(50.00)$ \\
$>40$ & \\
Q7. Can patients with unknown mitral valve & \\
diseases that have only mitral regurgitation \\
(rheumatic and nonrheumatic) be classified as \\
valvular atrial fibrillation? \\
Yes \\
$\begin{array}{l}\text { No } \\
\text { Decision according to the degree of mitral }\end{array}$ \\
ins
\end{tabular}
insufficiency

Q8. What is the degree of mitral insufficiency for the diagnosis of valvular atrial fibrillation in patients with ischemic mitral insufficiency?

$\begin{array}{lc}\geq 1^{\circ} & 2(0.89) \\ \geq 2^{\circ} & 16(7.14) \\ \geq 3^{\circ} & 33(14.73) \\ \text { Ischemic MR is NVAF } & 166(74.11) \\ \text { No idea } & 7(3.13)\end{array}$

Q9. Does mitral insufficiency decrease the thrombus formation in LA/LAA in patients with AF?

\begin{tabular}{lc} 
Yes & $41(18.30)$ \\
No & $97(43.30)$ \\
Only LA & $41(18.30)$ \\
Both of them & $30(13.39)$ \\
No idea & $15(6.70)$ \\
\hline
\end{tabular}

NVAF: Nonvalvular AF, LA: Left atrium, LAA: Left atrial appendage

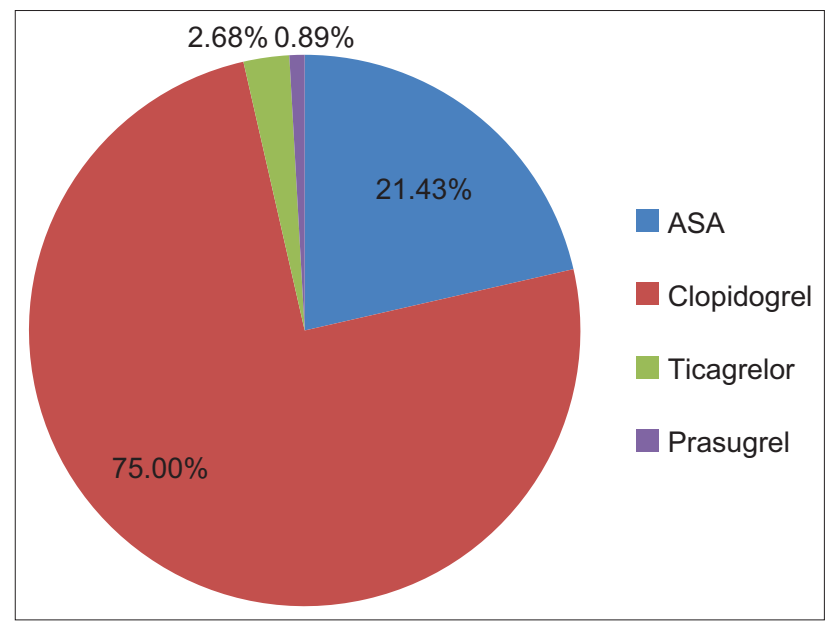

Figure 2: Antiplatelet agent preferences of physicians in atrial fibrillation patients using oral anticoagulants during acute coronary syndromes 


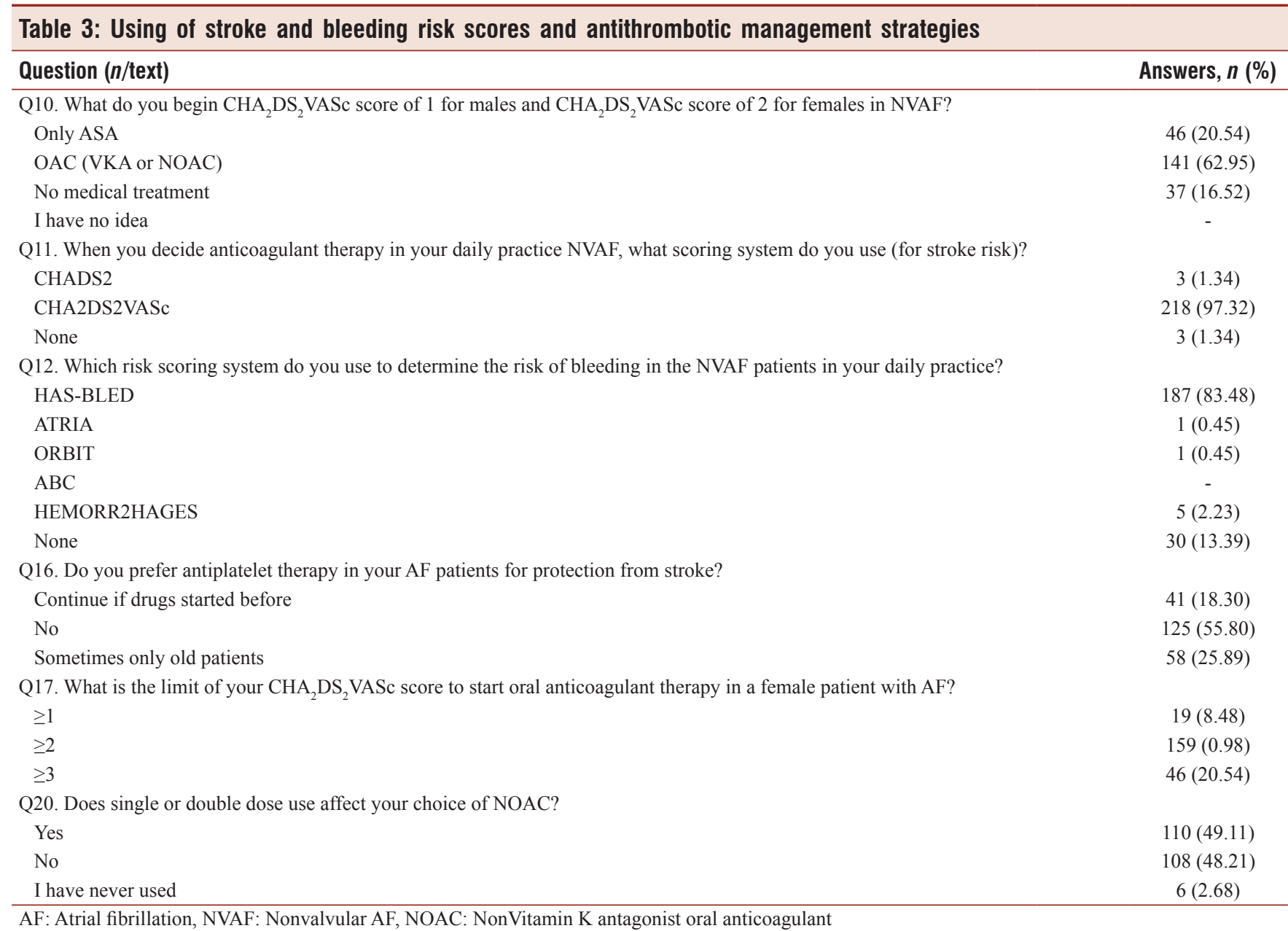

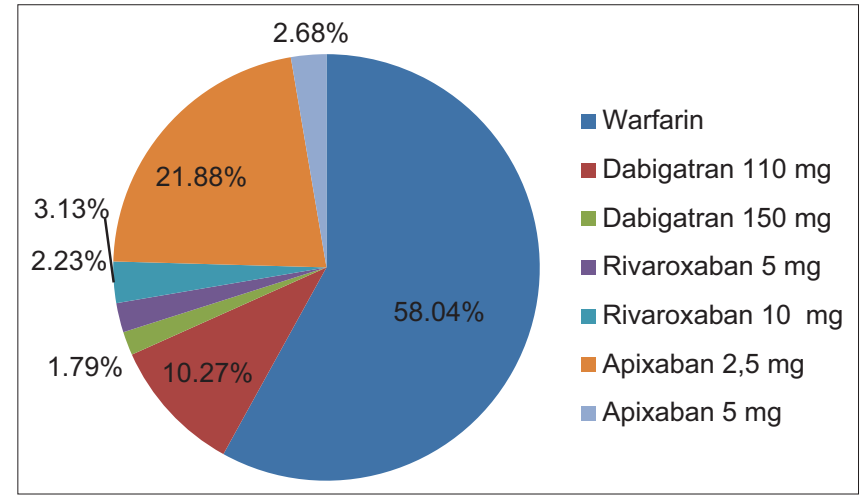

Figure 3: Physicians oral anticoagulants' preferences in atrial fibrillation patients with creatinin clearance $<30 \mathrm{ml} / \mathrm{dk}$

incompatibility. Furthermore, most of the physicians have thought to switch NOACs to warfarin in these conditions; drug side effects, stroke, and bleeding under NOACs. About $58 \%$ of the physicians preferred warfarin in AF patients with severe kidney diseases who had $\mathrm{CHA}_{2} \mathrm{DS}_{2}$ VASc score of 3 and HASBLEED score of 2 . The second preferred drug was apixaban $2.5 \mathrm{mg}$ in severe kidney diseases by physicians (22\%) [Figure 3]. Half of the physicians considered to start anticoagulation

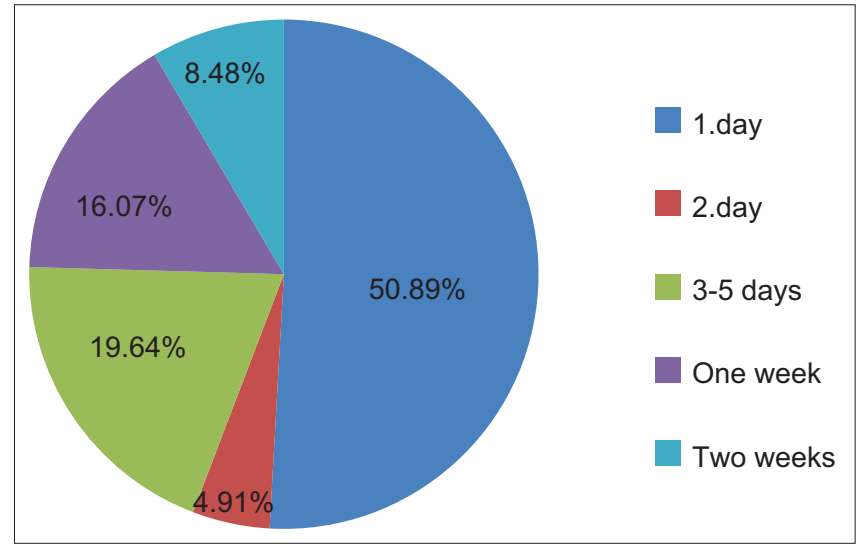

Figure 4: Oral anticoagulants therapies Initiation times by physicians after transient ischemic attack in patients with atrial fibrillation

after the $1^{\text {st }}$ day in AF patients with transient ischemic stroke [Figure 4 and Table 4].

Most of the physicians selected propafenone and amiodarone as the first-line agents for cardioversion (CV) in paroxysmal AF. Beta-blockers and digoxin were chosen by the majority of physicians (91\% and $71 \%$, respectively) as rate control 


\section{Table 4: Oral anticoagulant therapy at different scenarios}

Q14. What do you do if you detected 1,9 INR levels in eighty or above ages patient under warfarin treatment?

Q15. Which of the following factors is reason for not giving OAC despite the indication of oral anticoagulant treatment?

Advanced age

Education level

Renal failure (stage 3 and above)

History intracranial hemorrhage

Major GIS bleeding history

None

Q18. What do you do if renal functions of NVAF patient under NOAC therapy show progressive deterioration due to underlying chronic diseases (HT, DM, Vascular disease, etc.,) (GFR $<30 \mathrm{ml} / \mathrm{min})$ ?

Continue low dose of NOAC

Change to warfarin

Q20. Use single or double dose per day, do you influence your choice of NOAC?

Yes

$110(49.11)$

No

I have never used

Q21. Which antiplatelet agent do you prefer with oral anticoagulant therapy after acute coronary syndromes in AF patients?

Q22. Which cases do you switch warfarin to NOAC in NVAF patients? (Multiple options can be marked)

Directly

Low TTR levels $(<65 \%)$

Hemorrhage under warfarin therapy

Never

Q23. Which situations do you switch NOAC therapy to other NOAC therapy or warfarin in NVAF patients? (multiple options can be marked)

Stroke/TIA associated therapy

Hemorrhage associated therapy

Side effect associated therapy

No changing (focusing in trigger factors)

Q24. Which OAC do you prefer in AF patients that have 3 CHA2DS2-VASc score and 2 HAS-BLEED score if their creatinine clearance lowers $30 \mathrm{ml} / \mathrm{min}$ ?

\section{Warfarin}

Dabigatran $110 \mathrm{mg}$

Q25. How many days after do you recommend oral anticoagulant therapy to AF patients with transient ischemic stroke?

INR: International normalized ratio, AF: Atrial fibrillation, NVAF: Nonvalvular AF, NOAC: Nonvitamin K antagonist oral anticoagulant, OAC: Oral anticoagulant, GIS: Gastro-intestinal system, GFR: Glomerular filtration rate, TIA: Transient ischemic attack 


\begin{tabular}{lc}
\hline Table 5: Rhythm/rate control strategies & \\
\hline Question ( $\boldsymbol{n} /$ text) & Answers, $\boldsymbol{n}$ (\%) \\
\hline Q13.What is your first drug option in the & \\
pharmacological cardioversion of paroxysmal atrial & \\
fibrillation? & $31(13.84)$ \\
$\quad$ Beta blockers & $91(40.63)$ \\
Propafenone & $92(41.07)$ \\
Amiodarone & $7(3.13)$ \\
Verapamil-diltiazem & $3(1.34)$ \\
Digoxin & \\
Q19. Which option do you prefer in AF patients \\
that have ejection fraction below 40\% for long-term \\
heart rate control? (multiple options can be marked) \\
Digoxin & $159(70.98)$ \\
Amiodarone & $39(17.41)$ \\
Beta blockers & $203(90.63)$ \\
\hline
\end{tabular}

agents in AF patients with low ejection fraction [Table 5]. The last two questions (Q26, Q27) were about consent and address information.

\section{Discussion}

This survey has provided information about confusions and compatibilities of valvular and nonvalvular AF and usage of bleeding and risk scores in real life during the management of AF patients. In addition, the survey obtained physicians' perspectives in terms of managing specific AF patient groups and in special situations.

The definition of valvular and nonvalvular AF has become more important after emerging of NOACs. Previous guidelines defined nonvalvular AF in the absence of a mechanical prosthetic heart valve or moderate to severe mitral stenosis ${ }^{[8,9]}$ (usually of rheumatic origin). The trials about NOACs have excluded mechanical prosthetic heart valve and mitral stenosis. ${ }^{[10]}$ In this study, half of the physicians accepted $>40 \%$ of the patients were nonvalvular AF. These can be explained in three ways: (1) high prevalence of rheumatic valve diseases in our country due to the frequency of acute rheumatic fever, (2) nomenclature confusion of studies in literatures, and (3) physicians do not dominate the definitions in the current guidelines and are affected by the nomenclature confusions. More than half of the physicians in this survey evaluated mitral regurgitation as nonvalvular AF in patients with AF. Unlike this survey, in a previous study, most participants agreed that rheumatic mitral regurgitation was related to valvular AF. ${ }^{[3]}$ Perceptions of valvular AF are different among the studies because guidelines have different attitudes in valvular abnormalities other than prosthetic valves and mitral stenosis. Different designs of recent trials about NOACs led to confusions, gray zones in guidelines. While RELY trial excluded hemodynamically relevant valve diseases, ROCKET-AF study included patients who underwent annuloplasty, valvuloplasty, and commissurotomy. Furthermore, ARISTOTLE and ENGAGE trials did not include patients with moderate-to-severe mitral stenosis. ${ }^{[1]}$ Therefore, 2016 ESC guideline eliminated valvular AF to avoid confusion. ${ }^{[1]}$
Some risk scoring methods were developed to evaluate the risk of stroke in the late 1990s in small cohort studies. The most commonly used and recommended score system by ESC guidelines is $\mathrm{CHA}_{2} \mathrm{DS}_{2}$ VASc score. This scoring method firstly took place in ESC guidelines in $2010 .^{[12,13]}$ In the light of the guidelines, almost all physicians (97\%) preferred $\mathrm{CHA}_{2} \mathrm{DS}_{2}$ VASc scoring method in AF patients. More than half of the physicians agreed to start OACs with $\mathrm{CHA}_{2} \mathrm{DS}_{2} \mathrm{VASc}$ score of 1 for males and 2 for females. In a previous study, most of the physicians (78\%) thought that no additional research for starting anticoagulants when $\mathrm{CHA}_{2} \mathrm{DS}_{2}$ VASc score $\geq 1$ in AF patients. ${ }^{[14]}$ Some studies have shown that $\mathrm{CHA}_{2} \mathrm{DS}_{2} \mathrm{VASc}$ score of $\geq 1$ for male and CHA2DS2VASc score of $\geq 2$ for females was related with stroke and they would benefit from oral anticoagulant agents. OACs should be considered for patients after balancing the expected stroke risk, bleeding risk, and patient preference. ${ }^{[6,15]}$ In this survey, $70 \%$ of the physicians accepted the anticoagulant starting limit as $\mathrm{CHA}_{2} \mathrm{DS}_{2}$ VASc of $\geq 2$ for females, but current guidelines revealed that female gender alone does not appear to increase stroke risk in the absence of other stroke risk factors. ${ }^{[16,17]}$ There are some differences about the risk scoring system among guidelines. Unlike the American guidelines, ${ }^{[5]}$ European guidelines ${ }^{[1]}$ do not recommend antiplatelet agents in AF patients with a $\mathrm{CHA}_{2} \mathrm{DS}_{2}$ VASc score of $=0$.

Most of the physicians (83\%) preferred HAS-BLED bleeding risk score in $\mathrm{AF}$ as this score has been derived by using a real-world cohort of $3978 \mathrm{AF}$ patients and it is a simple bleeding risk score system for physicians. ${ }^{[18]}$ Frequent use of bleeding risk scores by physicians in AF patients with high thromboembolic risk may be due to ensure the safety of patients. In a study, it was shown that $26 \%$ of AF patients with aged 80 years and over had stopped using OACs therapies for safety reasons in the $1^{\text {st }}$ year. Especially, the intracranial hemorrhage risk related to fall is overestimated. ${ }^{[19]}$

The physicians usually gave different responses about management of the patients with AF in specific scenarios. One of them was the management of elderly patients under subtherapeutic warfarin treatment. European guidelines ${ }^{[1]}$ depicted that OACs should not be avoided only due to age in elderly patients because of the higher risk of stroke in these people, but comorbidities should be taken into account. Although the most important contraindication of $\mathrm{OAC}$ therapies was intracranial hemorrhage in this survey, more than half of the physicians considered using OACs treatment after intracranial bleeding. Previous studies shown that less than half of the physicians have prescribed OAC therapies in geriatric syndromes, cognitive disorders and fall risk in elderly AF patients. Physicians are worried about prescribing OACs because of the high fall risk in elderly people. Furthermore, physicians feel responsible for intracranial hemorrhage after fall in the elderly patients using OACs. Hence, some physicians prefer ASA treatment in older AF patients for their safety and they consider that ASA is safer than warfarin and nearly as effective as it is. However, it has 
been revealed that AF patients with high thromboembolic risk would need to fall about three hundred times a year for the risk of intracranial hemorrhage. ${ }^{[19]}$ The guidelines define that intracranial hemorrhage after anticoagulant interruption causes late ischemic strokes and death. Furthermore, guidelines point out that uncontrolled hypertension, aneurysm, triple antiagregan/anticoagulant therapy is not absolute contraindication, while only spontaneous intracranial hemorrhage is precisely contraindicated for anticoagulants. ${ }^{[20]}$

While approximately two-thirds of physicians preferred to switch NOAC to warfarin, one-third of them preferred to decrease NOACs' doses in severe kidney failure diseases (glomerular filtration rate $<30 \mathrm{ml} / \mathrm{min} / \mathrm{m}^{2}$ ). There are not adequate data on the use of NOACs for stroke prevention in $\mathrm{AF}$ patients with severe chronic kidney disease because NOACs trials essentially excluded patients with $\mathrm{CrCl}$ of $<30 \mathrm{ml} / \mathrm{min} / \mathrm{m}^{2}$ (except for a few patients on apixaban with $\mathrm{CrCl}$ of $<30 \mathrm{ml} / \mathrm{min} / \mathrm{m}^{2}$ ). Apixaban is approved by Food and Drug Administration in patients with creatinine clearance $<15 \mathrm{~mL} / \mathrm{min}$ or end-stage renal disease. However, the recommendations are based on pharmacokinetic and pharmacodynamic data of apixaban in severe kidney failure. In a meta-analysis of 43850 subjects, apixaban had a significantly lower bleeding rate than warfarin and thromboembolic event risks were similar in severe kidney diseases. ${ }^{[21]}$ Today the European guidelines ${ }^{[22]}$ suggest that apixaban, edoxaban, and rivaroxaban can be used in specific patients with $\mathrm{CrCl}$ of $<30 \mathrm{ml} / \mathrm{min} / \mathrm{m}^{2}$. However, the lack of adequate trials and the difference of guidelines about renal disease may cause confusions and conflictions in physicians. Most of the physicians preferred clopidogrel as an antiplatelet agent in patients with $\mathrm{AF}$ who had acute coronary syndromes, 2016 ESC guideline and 2017 DAPT focused data recommends clopidogrel, ASA and NOACs as a triple therapy for acute coronary syndromes..$^{[1]}$ The NOACs are preferred because of their simple medication, causing less bleeding than warfarin in most cases and providing protection from stroke as warfarin. ${ }^{[22]}$ For these reasons, the guidelines recommend the initiation of NOACs rather than warfarin, in patients with $\mathrm{AF}^{\left[{ }^{[1]}\right.}$

There are no more randomized comparative trails of switching to NOACs versus VKA or NOACs treatment. ${ }^{[23]}$ Switching NOAC-NOAC/NOAC-warfarin was found related to stroke and bleeding in the few previous studies. In a study, warfarin was preferred to NOACs because of previous VKA use, chronic renal failure, ischemic heart disease, and dabigatran use. The patients who preferred warfarin were young $(<55)$ and had low $\mathrm{CHA}_{2} \mathrm{DS}_{2}$ VASc score. Apixaban was tolerated by most patients using NOACs in this study. Hence, the patients who used other NOACs initially switched to apixaban during the study. ${ }^{[24]}$ Users of apixaban had better persistence, this difference in persistence should be further explored. In this survey, physicians decided to switch drugs (NOAC-NOAC/NOAC-warfarin) because of stroke and bleeding under therapy (especially for secondary prevention), side effects and ease of use.
ESC guidelines ${ }^{[25]}$ recommend that OACs may be continued (according to prescription and label) or started 1 day after a TIA after exclusion of intracranial bleeding by imaging modalities. However, half of the physicians in this survey preferred to start OACs 1 day after TIA. This shows that physicians are concerned about intracranial bleeding, they may not have enough information and they have confusions about this status. Physicians' NOACs preferences were similar because there are no data in guidelines about NOACs preference. ${ }^{[1]}$

Most of the physicians preferred propafenone and amiodarone in paroxysmal $\mathrm{AF}$ as an antiarrhythmic agent and they chose beta blockers and digoxin for rate control in patients with low ejection fraction. European guideline ${ }^{[1]}$ recommends flecainide and propafenone in patients without significant structural heart diseases and considers beta blockers and digoxin for long term rate control in $\mathrm{LVEF}<40 \%$ of patients. However, amiodarone could easily be found in our country which might be the reason for this preference. If there were more antiarrhythmic agents in our country, the physicians might have had confusions and differences about drug selections.

\section{Study limitations}

We did not group physicians according to their specialities and experiences. Perhaps we would have more homogenous responses if we had organized a survey with the same specialty and experience. And also we could not reach more physicians, so it was a limited study.

\section{Conclusion}

In this survey, the definitions of valvular and nonvalvular AF, specific patients' managements were heterogeneous among physicians. This survey suggests that explorative data of NOACs phase III trials cannot convince most physicians and they have confusions and believe there is insufficient evidence about subgroup analyzes. Prospective multi-centered large randomized controlled trials focused on specific subgroups as kidney diseases, frail old patients, etc., and specific conditions are needed. Nowadays, the studies of NOACs with subgroups are underway and the results are expected in the world of medicine.

\section{Financial support and sponsorship}

Nil.

\section{Conflicts of interest}

There are no conflicts of interest.

\section{RefEREnCES}

1. Kirchhof P, Benussi S, Kotecha D, Ahlsson A, Atar D, Casadei B, et al. 2016 ESC guidelines for the management of atrial fibrillation developed in collaboration with EACTS. Europace 2016;18:1609-78.

2. Ogilvie IM, Newton N, Welner SA, Cowell W, Lip GY. Underuse of oral anticoagulants in atrial fibrillation: A systematic review. Am J Med 2010;123:638-45.e4.

3. Potpara TS, Lip GY, Larsen TB, Madrid A, Dobreanu D, Jędrzejczyk-Patej E, et al. Stroke prevention strategies in patients with atrial fibrillation and heart valve abnormalities: Perceptions of 'valvular' 
atrial fibrillation: Results of the European Heart Rhythm Association Survey. Europace 2016;18:1593-8.

4. Molteni M, Polo Friz H, Primitz L, Marano G, Boracchi P, Cimminiello $\mathrm{C}$, et al. The definition of valvular and non-valvular atrial fibrillation: Results of a physicians' survey. Europace 2014;16:1720-5.

5. January CT, Wann LS, Alpert JS, Calkins H, Cigarroa JE, Cleveland JC Jr., et al. $2014 \mathrm{AHA} / \mathrm{ACC} / \mathrm{HRS}$ guideline for the management of patients with atrial fibrillation: Executive summary: A report of the American College of Cardiology/American Heart Association Task Force on Practice Guidelines and the Heart Rhythm Society. Circulation 2014;130:2071-104.

6. Steffel J, Verhamme P, Potpara TS, Albaladejo P, Antz M, Desteghe L, et al. The 2018 European Heart Rhythm Association practical guide on the use of non-Vitamin $\mathrm{K}$ antagonist oral anticoagulants in patients with atrial fibrillation. Eur Heart J 2018;39:1330-93.

7. Heidbuchel H, Verhamme P, Alings M, Antz M, Diener HC, Hacke W, et al. Updated European Heart Rhythm Association Practical Guide on the use of non-Vitamin $\mathrm{K}$ antagonist anticoagulants in patients with non-valvular atrial fibrillation. Europace 2015;17:1467-507.

8. Barnes GD, Ageno W, Ansell J, Kaatz S; Subcommittee on the Control of Anticoagulation of the International Society on Thrombosis and Haemostasis. Recommendation on the nomenclature for oral anticoagulants: Communication from the SSC of the ISTH. J Thromb Haemost 2015;13:1154-6.

9. Baumgartner H, Falk V, Bax JJ, De Bonis M, Hamm C, Holm PJ, et al. 2017 ESC/EACTS guidelines for the management of valvular heart disease. Eur Heart J 2017:38:2739-91.

10. Martins RP, Galand V, Colette E, Behar M, Pavin D, Leclercq C, et al. Defining nonvalvular atrial fibrillation: A quest for clarification. Am Heart J 2016;178:161-7.

11. Ozer N. Clinical studies conducted with new oral anticoagulants in atrial fibrillation: Which oral anticoagulant can be considered for which case in light of the clinical studies? Arch Turk Soc Cardiol 2016;44:33-40.

12. Lip GY, Nieuwlaat R, Pisters R, Lane DA, Crijns HJ. Refining clinical risk stratification for predicting stroke and thromboembolism in atrial fibrillation using a novel risk factor-based approach: The Euro Heart Survey on atrial fibrillation. Chest 2010;137:263-72.

13. Kirchhof P, Curtis AB, Skanes AC, Gillis AM, Samuel Wann L, John Camm A, et al. Atrial fibrillation guidelines across the atlantic: A comparison of the current recommendations of the European Society of Cardiology/European Heart Rhythm Association/European Association of Cardiothoracic Surgeons, the American College of Cardiology Foundation/American Heart Association/Heart Rhythm Society, and the Canadian Cardiovascular Society. Eur Heart J
2013;34:1471-4

14. Dagres N, Bongiorni MG, Dobreanu D, Madrid A, Svendsen JH, Blomström-Lundqvist $\mathrm{C}$, et al. Current investigation and management of patients with syncope: Results of the European Heart Rhythm Association Survey. Europace 2013;15:1812-5.

15. Olesen JB, Lip GY, Hansen ML, Hansen PR, Tolstrup JS, Lindhardsen J, et al. Validation of risk stratification schemes for predicting stroke and thromboembolism in patients with atrial fibrillation: Nationwide cohort study. BMJ 2011;342:d124.

16. Chao TF, Liu CJ, Wang KL, Lin YJ, Chang SL, Lo LW, et al. Should atrial fibrillation patients with 1 additional risk factor of the CHA2DS2-VASc score (beyond sex) receive oral anticoagulation? J Am Coll Cardiol 2015;65:635-42.

17. Mikkelsen AP, Lindhardsen J, Lip GY, Gislason GH, Torp-Pedersen C, Olesen JB, et al. Female sex as a risk factor for stroke in atrial fibrillation: A nationwide cohort study. J Thromb Haemost 2012;10:1745-51.

18. Ozeke O, Aras S, Baser K, Sen F, Kirbas O, Cay S, et al. Defensive medicine due to different fears by patients and physicians in geriatric atrial fibrillation patients and second victim syndrome. Int $\mathrm{J}$ Cardiol 2016;212:251-2

19. Camm AJ, Kirchhof P, Lip GY, Schotten U, et al. European Heart Rhythm Association, European Association for Cardio-Thoracic Surgery, Guidelines for the management of atrial fibrillation: The Task Force for the Management of Atrial Fibrillation of the European Society of Cardiology (ESC). Eur Heart J 2010;31:2369-429.

20. Wilson D, Seiffge DJ, Traenka C, Basir G, Purrucker JC, Rizos T, et al. Outcome of intracerebral hemorrhage associated with different oral anticoagulants. Neurology 2017;88:1693-700.

21. Chokesuwattanaskul R, Thongprayoon C, Tanawuttiwat T, Kaewput W, Pachariyanon P, Cheungpasitporn W, et al. Safety and efficacy of apixaban versus warfarin in patients with end-stage renal disease: Meta-analysis. Pacing Clin Electrophysiol 2018;41:627-34.

22. Wagstaff AJ, Overvad TF, Lip GY, Lane DA. Is female sex a risk factor for stroke and thromboembolism in patients with atrial fibrillation? A systematic review and meta-analysis. QJM 2014;107:955-67.

23. Verdecchia P, Angeli F, Aita A, Bartolini C, Reboldi G. Why switch from warfarin to NOACs? Intern Emerg Med 2016;11:289-93.

24. Hellfritzsch M, Husted SE, Grove EL, Rasmussen L, Poulsen BK, Johnsen SP, et al. Treatment changes among users of non-Vitamin K antagonist oral anticoagulants in atrial fibrillation. Basic Clin Pharmacol Toxicol 2017;120:187-94.

25. Olesen JB, Lip GY, Kamper AL, Hommel K, Køber L, Lane DA, et al. Stroke and bleeding in atrial fibrillation with chronic kidney disease N Engl J Med 2012;367:625-35. 